\title{
Percepções de professores de química no período da pandemia de COVID-19 sobre o uso de jogos virtuais no ensino remoto
}

\author{
Perceptions of chemistry teachers during the COVID-19 pandemic on the use of virtual games in \\ remote learning
}

Percepciones de los profesores de química en el período de la pandemia de COVID-19 sobre el uso de juegos virtuales en la educación remota

\section{Resumo}

Os jogos virtuais possibilitam interesse e a participação discente assim como podem possibilitar atenção, criatividade, coordenação motora, concentração, dentre outras vantagens. Diante disto, esta pesquisa teve como objetivo: compreender o que os professores de química do ensino médio de uma escola do município de Camocim-CE pensam com relação ao uso e aplicabilidade de jogos educativos virtuais levando-se em consideração suas concepções pedagógicas e os processos de formação continuada oriundos do ofício da docência. Trata-se de uma pesquisa qualitativa, do tipo exploratória, realizada nos meses de outubro a dezembro de 2020 em uma escola de Ensino Médio, localizada no município de Camocim-CE, cujos sujeitos foram três professores de química. Como técnica de coleta de dados utilizou o questionário, que devido aos cuidados com a pandemia do COVID-19, foi aplicado remotamente, através de aplicativo de mensagem. Com os dados coletados pudemos perceber professores progressistas e tradicionalistas, e que o uso dos jogos virtuais para alguns foi de suma importância para o ensino de conteúdos de química. Inferimos os jogos virtuais educativos, se mostraram eficientes e necessários, principalmente diante da realidade que estamos vivenciando com a pandemia do COVID-19.

Palavras-chave: Ensino de química; Ferramentas de ensino; Pandemia.

\begin{abstract}
The virtual games enable interest and participation of the student, as well as can enable attention, creativity, motor coordination, concentration, among other advantages. The objective of this research was to understand the perceptions of high school teachers in a school in the municipality of Camocim-CE regarding the use and applicability of games in times of pandemic. This is a qualitative, exploratory research, carried out in a high school, located in the municipality of Camocim-CE, whose subjects were chemistry teachers. As a data collection technique, we used the questionnaire, which due to care for the COVID-19 pandemic, was applied remotely, through a message application. With the collected data we could perceive progressive and traditionalist teachers, and that the use of virtual games for some was of paramount importance for the teaching of chemistry contents. We infer the educational virtual games, proved to be efficient and necessary, especially given the reality that we are experiencing with the COVID-19 pandemic.
\end{abstract}

Keywords: Chemistry teaching; Teaching tools; Pandemic.

\section{Resumen}

Los juegos virtuales posibilitan el interés y la participación del alumno, así como pueden posibilitar atención, creatividad, coordinación motora, concentración, entre otras ventajas. Investigación tuvo como objetivo: Comprender 
las percepciones de profesores de la Enseñanza Media de una escuela del municipio de Camocim-CE, en cuanto al uso y aplicabilidad de juegos en tiempos de pandemia. Se trata de una investigación cualitativa, del tipo exploratorio, realizado en una escuela de Enseñanza Media, ubicada en el municipio de Camocim-CE, cuyos sujetos fueron profesores de química. Como técnica de recolección de datos utilizó el cuestionario, que debido a los cuidados con la pandemia de COVID-19, fue aplicado remotamente, a través de aplicación de mensaje. Con los datos recopilados pudimos percibir profesores progresistas y tradicionalistas, y que el uso de los juegos virtuales para algunos fue de suma importancia para la enseñanza de contenidos de química. Inferimos los juegos virtuales educativos, se mostraron eficientes y necesarios, principalmente ante la realidad que estamos viviendo con la pandemia del COVID-19.

Palabras clave: Enseñanza de la química; Herramientas didácticas; Pandemia.

\section{Introdução}

Use Atualmente, quando se analisa o modelo de ensino da maioria das escolas brasileiras, é perceptível ainda a presença de uma abordagem tradicionalista predominante, na qual a maioria dos professores encontra-se no centro do processo de ensino aprendizagem e os discentes atuam como meros coadjuvantes, que pouco refletem sobre o que está sendo ensinado. Esse processo, para os discentes, se converte em um desinteresse geral sobre os conteúdos abordados no currículo escolar de maneira geral (Lima Filho et al., 2011; Nicola \& Paniz, 2016).

Entretanto, a realidade que se vislumbra diante da atual "sociedade da informação" impacta diretamente o dia a dia escolar, bem como também se reflete nas metodologias utilizadas pelos professores em sala de aula. Para Bitencourte et al., (2018), a era da informação tecnológica que estamos vivenciando atualmente é resultado de um grande número de informações disponíveis e estocadas através de sons, imagens, vídeos, entre outros, em substituição as informações repassadas apenas de forma oral. Todavia, estes fatores levam a exigência de professores que tenham uma aproximação maior com as Tecnologias Digitais de informação e comunicação (TDIC's) em educação e possam aplicá-las em suas aulas. Tais realidades fazem com que os professores tenham que utilizar novas alternativas para tornar suas aulas mais atrativas, principalmente diante da pandemia do COVID-19, iniciada em meados de março de 2020.

Sabe-se que os jogos auxiliam na motivação discente, por meio dos desafios que estas atividades lúdicas proporcionam e por conseguirem manter a atenção dos alunos mesmo que estes estejam desinteressados, pois o desejo de ganhar o jogo leva o indivíduo a refletir e redimensionar sua aprendizagem (Shaw \& Ribeiro, 2014).Conforme Prensky (2012), os jogos digitais podem ser definidos como um conjunto de brincadeiras e/ou atividades de entretenimento com estruturações que contenham um ou mais elementos, a saber: regras delimitadas, metas ou objetivos a serem alcançados que possam resultar em um feedback para os jogadores e que estimulem a motivação, a competição, os desafios, a interação, a representação ou enredo.

Para Martins e Giraffa (2014), este conceito é oriundo dos estudos relacionados a Gamificação, que consistem na utilização de elementos empregados em jogos e brincadeiras em atividades que na sua essência, não envolvem o uso de jogos, aplicando-se, portanto, a sala de aula e em atividades voltadas à educação e aos processos de ensino e aprendizagem. Jacinto Junior et al., (2021), descrevem em seu trabalho a utilização de vários tipos de jogos, como: as paródias, jogos de tabuleiro e de cartas, jogos da memória, bingo, quizzes onlines e peças teatrais; aplicados ao ensino das disciplinas de Química, Física e Biologia na educação básica. Para Scherer e Silva Miranda (2013) e Savi e Ulbricht (2008), o professor, ao propor o uso de um jogo em sala de aula, deve prover os recursos necessários para a execução da atividade planejada e acompanha-la visando o favorecimento da aprendizagem discente, favorecendo objetivos de aprendizagem que estejam além do ato de simplesmente jogar. Na literatura podem ser encontrados muitos trabalhos que tratam da aplicação de jogos didáticos em sala de aula, a saber: Benedetti Filho et al., (2019) realizaram a aplicação de um jogo didático virtual sobre a História da Química utilizando a plataforma computacional 'Construct 2®'; Romano et al., (2017) adaptaram o jogo de cartas e tabuleiro Perfilß, da marca registrada da companhia de brinquedos 'Grow®', para estimular a aprendizagem de conteúdos relacionados à Tabela 
Periódica; Santos \& Melo (2020), utilizaram a peça teatral 'Heróis da Ciência' para estimular a aprendizagem de ciências em alunos com deficiência.

Quando se mistura ludicidade e tecnologias educacionais no processo de ensino aprendizagem, este ocorre de forma muito mais prazerosa e significativa, tendo em vista que o uso de jogos como metodologia alternativa permite uma aprendizagem de conteúdos por meio de brincadeiras e do estímulo do raciocínio logico (Cunha, 2012). A utilização de jogos virtuais pode atrair a atenção e motivar o interesse e a participação discente, promovendo a quebra da rotina tão presente nas aulas tradicionais, desafiando-o a aprender de forma lúdica, pois os jogos podem possibilitar o desenvolvimento da criatividade, coordenação motora, concentração, dentre outras diversas vantagens (Freitas \& Mancini, 2019).

É a partir deste olhar investigativo que se pretende analisar sob a perspectiva docente o uso dos jogos em sala de aula. O interesse por essa temática surgiu a partir das disciplinas de Estágio Supervisionado na graduação em Licenciatura Plena em Química, onde se percebeu que determinados professores regentes utilizavam metodologias de jogos em suas aulas, com isso surgiu o interesse em compreender melhor como a metodologia de jogos servia para avaliar. Ademais, devido a pandemia que possibilitou a utilização do ensino remoto nas escolas, percebeu-se a necessidade de um olhar mais específico sobre o uso dos jogos virtuais, que tem se mostrado muito eficiente como ferramenta lúdica.

Todas essas questões levantadas direcionam um olhar reflexivo sobre a pandemia do Covid-19 percebendo a carência no tocante a necessidade do uso de jogos virtuais no processo de ensino remoto de química; e para isto se reconhece o professor como um instigador dos processos de aprendizagem. Diante dessa realidade é feito o seguinte questionamento: como os professores de Química de uma escola de Ensino Médio percebem o uso de jogos virtuais e sua aplicabilidade em sala de aula?

A partir desta indagação, esta pesquisa tem por finalidade compreender o que os professores de Química do Ensino Médio de uma escola do município de Camocim-CE, pensam com relação ao uso e aplicabilidade de jogos educativos virtuais levando em consideração suas concepções pedagógicas e os processos de formação continuada oriundos do ofício da docência. Espera-se que este estudo contribua para o entendimento sobre a importância dos jogos, tendo como base a percepção dos professores de química e suas vivencias com a utilização dessa ferramenta em tempos de pandemia, bem como seus impactos no processo de ensino de química.

\section{Metodologia}

Este estudo trata-se de uma pesquisa de natureza aplicada, com abordagem qualitativa, que tem por finalidade buscar uma resposta para o objeto de estudo em questão, possuindo um caráter exploratório (Lüdke \& André, 2013). Minayo (2001) assevera que:

A pesquisa qualitativa responde a questões muito particulares. Ela se preocupa, nas ciências sociais, com um nível de realidade que não pode ser quantificado. Ou seja, ela trabalha com um universo de significados, motivos, aspirações, crenças, valores e atitudes, o que corresponde a um espaço mais profundo das relações, dos processos e dos fenômenos que não podem ser reduzidos à operacionalização das variáveis (p. 21).

Para a autora, o pesquisador terá que observar de forma mais ampla os fenômenos sociais. Diante desta proposta para investigação, acredita-se que este seja o caminho mais adequado para gerar dados relevantes. Dessa forma, a pesquisa foi realizada nos meses de outubro a dezembro de 2020, no município de Camocim-CE, em uma escola de Ensino Médio, tendo como sujeitos da pesquisa três professoras de química que atuam na escola supracitada. 


\subsection{Instrumentos de coleta de dados e execução da pesquisa}

Para participarem da pesquisa, os sujeitos foram informados sobre a intenção da investigação e apresentados ao Termo de Consentimento Livre e Esclarecido - TCLE solicitando a anuência do participante. Em seguida, foram explicados que durante a coleta de dados seriam omitidos os nomes dos entrevistados, respeitando a integridade e o sigilo das suas respostas. Logo após eles serem informados sobre a pesquisa, foi feita a entrega do instrumental da coleta de dados.

Para a coleta de dados utilizou-se o questionário, que para Gil (2008) pode ser definido como: a técnica de investigação composta por um número mais ou menos elevado de questões apresentadas por escrito às pessoas, tendo por objetivo o conhecimento de opiniões, crenças, sentimentos, interesses, expectativas, situações vivenciadas, entre outros. Este instrumento de coleta de dados se tornou o mais adequado para o desenvolvimento deste estudo, diante da realidade que estamos vivenciando com a pandemia do COVID-19. O questionário foi aplicado de forma virtual, através de aplicativo de mensagens. e dividia-se em duas seções: a primeira apresentava nove questões (sendo duas questões objetivas e sete questões subjetivas) que visavam caracterizar os sujeitos da pesquisa por meio das informações a seguir: nome; sexo; idade; ano em que obteve o título de graduação em outro curso de licenciatura e/ou em Química e o tempo de docência na educação básica, contendo dados relativos à carga horária, aos turnos de trabalho e a motivação do professor ao escolher se graduar em Química.

A segunda seção do questionário continha nove questões subjetivas, com o intuito de investigar a percepção do professor em relação ao uso de jogos virtuais no ensino de química frente as suas concepções pedagógicas, aos processos de formação continuada e aos desafios da era digital em tempos de pandemia. Percebeu-se demora no retorno do questionário pelos professores, justificado pelo aumento significativo de trabalho devido ao ensino remoto. As respostas obtidas através de sua aplicação foram transcritas de forma ipsis litteris para este trabalho, tendo o cuidado de garantir o sigilo e a integridade dos participantes.

\subsection{Caracterização dos sujeitos da pesquisa}

Responderam à pesquisa três professores, dos quais utilizamos a nomenclatura Margarida, Girassol e Crisântemo para identificá-los. Na caracterização dos sujeitos foram coletados dados de natureza qualitativa e quantitativa conforme relatado no tópico anterior.

Todos os participantes eram do sexo feminino, estando entre 36 e 45 anos de idade. Buscou-se conhecer o ano de formação para compreendermos o perfil dos sujeitos, assim como percebermos que realidades trazem no tocante às vivências na docência. Suas respostas resultaram nas seguintes informações: Margarida se formou em Licenciatura em Química em 2002 com 18 anos de vivência em sala de aula; Girassol se formou em Licenciatura em Química em 2015, mas já possuía 11 anos de docência devido a graduação em Licenciatura Plena em matemática; e Crisântemo, semelhante a Girassol, se formou em Licenciatura em Química em 2014 tendo 17 anos de docência devido a formação em Licenciatura Plena em Matemática.

Observa-se que as professoras trazem uma prática pedagógica madura devido o tempo de experiência de ensino, não se enquadrando na modalidade de docentes que estão no início da docência. Elas já possuem uma identidade profissional estabelecida e esta influência de maneira significativa na regência de sala de aula e na condução das aulas; na ação pedagógica e na reflexão sobre o processo de ensino-aprendizagem discente em meio ao enfrentamento dos imprevistos e dos novos desafios impostos socialmente na atualidade.

O tempo de formação informada por Margarida, Girassol e Crisântemo, leva-nos a inferir que os participantes apresentam vários anos de experiência em sala de aula, o que lhes permite contornar os imprevistos que vão surgindo no dia a dia escolar, planejando práticas e metodologias, pois para o exercício da profissão docente é exigido que os professores sejam flexíveis diante das eventualidades, em constante adaptação as mudanças (Domenico et al., 2015). Durante os estágios 
supervisionados é comum se ouvir que os professores "devem ter jogo de cintura".

Com relação as informações referentes a carga horária e turno de docência os seguintes dados foram revelados: Margarida possui 200h e trabalha nos turnos manhã, tarde e noite; Girassol possui 290 h/a e trabalha nos três turnos; Crisântemo possui $200 \mathrm{~h}$ e trabalha nos turnos manhã e tarde. Nesse ponto percebe-se um aspecto relevante quanto à carga horária excessiva do professor em sala de aula, e que pode refletir em uma síndrome bastante discutida nos dias atuais que é a síndrome de Burnout (caracterizada por uma reação ao estresse excessivo relacionado ao trabalho), que leva o profissional ao esgotamento, acarretando na improdutividade profissional desenvolvidas pelo excesso de trabalho (Carlotto, 2011). Este fato é corroborado por Oliveira (2006) quando afirma que:

Os professores são, em geral, considerados os principais responsáveis pelo desempenho dos alunos, da escola e do sistema, no contexto atual de reformas educacionais e de uma nova regulação educativa. Diante das variadas funções que a escola pública assume, os professores encontram-se frequentemente diante da necessidade de responder às exigências que estão para além de sua formação (p. 212).

Diante disto, o docente carece de tempo para descanso e hobbies para poder descansar, evitando que desenvolva a Síndrome de Burnout e demais problemas oriundos do excesso de trabalho. Outra indagação buscou saber o que levou os três participantes a escolha pela profissão, com isso obtivemos as afirmações a seguir:

"Porque a disciplina desperta minha curiosidade e adoro a explicação que a mesma nos traz para as coisas que nos rodeia. Relação de amor" (Margarida).

"Na verdade, não decide, cursava administração e logo depois matemática, mais por alguns empecilhos tive que trancar. Logo após cursei vestibular para química e logo após as primeiras aulas me apaixonei perdidamente, $e$ nunca mais sai. Costumo dizer que a química me escolheu e não eu ela" (Girassol).

"Eu sempre tive muita afinidade com as disciplinas da área de ciências da natureza, mas o que me fez eu me tornar uma professora de química foi um professor que eu tinha no ensino médio chamado Marcelo Lustosa era um profissional inspirador e foi nele que me inspirei tenho outra formação trabalhei nessa outra profissão (Direito) mas o que me realiza é a docência" (Crisântemo).

Os relatos nos levam a inferir que a escolha pela profissão vai além do campo financeiro e que, a identificação com a profissão é algo relevante na afirmação de Margarida, Girassol e Crisântemo. Recorremos à Vaillant e Garcia (2012) ao afirmarem que "aprendemos a ser docentes quando somos conscientes do que fazemos e do porquê o fazemos; quando damos razões e refletimos sobre as origens e consequências de nossas condutas e das dos demais" (p. 92). A fala de Margarida, Girassol e Crisântemo vai ao encontro da formação e identidade do profissional educador, onde suas falas trazem o reflexo de sua história vão ao encontro da satisfação como a profissão.

\section{Resultados e Discussão}

Os resultados e a discussão desta pesquisa foram divididos em duas categorias: a primeira diz respeito a aplicação de jogos em sala de aula e suas relações com as correntes pedagógicas e ideológicas inerentes a formação de cada professor, bem como aos seus processos de formação continuada, visto que o professor também é um sujeito participativo em relação a práxis pedagógica; e a segunda diz respeito a percepção dos professores quanto a utilização dos jogos virtuais em tempos de pandemia frente aos novos desafios impostos pela era digital e sua inclusão dentro do cotidiano escolar. 


\subsection{As correntes ideológicas e a formação continuada dos professores de química frente a utilização de jogos em sala de} aula

A formação continuada de professores é uma realidade que deve estar presente na vida do docente, pois através dela o professor pode fazer uma revisão de suas próprias ações com a finalidade de torná-lo autônomo profissionalmente, estimulando-o a rever e reanalisar sua práxis pedagógica. $\mathrm{O}$ ato de estabelecer uma crítica reflexiva sobre si mesmo, os torna sujeitos ativos do processo de formação (Person et al., 2019). Pautados nessa realidade e tendo como foco a temática sobre os jogos virtuais, buscou-se conhecer o perfil dos professores em meios aos processos de formação continuada e suas compreensões quanto à utilização dos jogos didáticos aplicados em sala de aula. As questões a seguir buscam compreender como cada docente se auto identifica em relação as suas concepções pedagógicas nas visões tradicionalistas ou renovadas da educação. Ao questionarmos os participantes obtivemos as seguintes respostas:

"Sou tradicional em relação a questão da disciplina e organização, mas me considero inovadora na metodologia, na visão que tenho sobre o sujeito aluno e na maneira de avaliar” (Margarida).

"Gosto muito de ser pesquisador, acho que todo momento você se descobri melhor e mais apito pra docência. Contudo o tradicional, não nos deixa nos afastar, ai gosto de unir os dois sou tradicional, mais bastante inovador quando a sala e a escola permite" (Girassol).

"Inovador, pois procuro sempre inovar em minha prática pedagógica, como trabalhar com música, jogos e práticas" (Crisântemo).

As práticas docentes analógicas estão cada vez mais sendo superadas pelas tecnologias digitais. O professor tradicional hoje está transitando entre um ensino tradicional e renovado, que é reflexo da inserção das Tecnologias Digitais Informação e Comunicação nas salas de aula (Carvalho et al., 2019). Dessa forma, esta nova realidade exige dos sistemas de ensino um investimento maior tanto na formação de professores quanto na escola. Portanto, o advento da Educação Digital acaba por influenciar e dinamizar a educação tradicional, promovendo novas práticas no processo educativo, através do aprendizado em espaços diferenciados. Ações como as descritas anteriormente se tornaram presentes no ano de 2020 com a pandemia do COVID-19, do qual levou muitos docentes a serem "obrigados" a abraçarem o ensino remoto, com suas limitações e com todos os entraves logísticos para sua inserção (Palú et al., 2020). E nesse transitar de tradicional e renovado, em meio a pandemia, buscamos conhecer as percepções desses docentes quanto a utilização de jogos virtuais no ensino de química ou ciências. As colocações dos participantes foram:

\section{“Considero uma metodologia atrativa ao aluno e que facilita a aprendizagem” (Margarida).}

"Bom, a melhor que você puder ver. O ensino de química através de jogos já foi e é tema de muitos artigos, pois há um resultado satisfatório em relação a aprendizagem os discentes, por isso sempre que dar procuro incrementar as aulas com jogos, mais confesso que nem sempre temos tempo para a aplicação” (Girassol).

“Uma prática que ajuda muito a incentivar aos alunos terem mais gosto e interesse pela disciplina” (Crisântemo).

Os relatos nos levam a inferir que os docentes reconhecem a importância dos jogos didáticos em sala de aula e seus reflexos na aprendizagem dos alunos. Concordamos com Cruz (2008) ao destacar que para a construção dos saberes necessários à aprendizagem é preciso que o aluno desenvolva competências pensantes que estimulem o aprender a aprender, a reflexão, a intervenção e a inovação. E para que os alunos sejam agentes dinâmicos deste processo é necessário que sejam estimulados a partir de metodologias ativas e atrativas, como as TIC's.

A inserção de jogos virtuais em sala de aula deve levar os discentes a uma aprendizagem contínua do conteúdo de 
suas disciplinas; a formação continuada de professores atualmente, deve estar acompanhada das TICs, pois a sociedade "cobra inconscientemente" sua inserção na escola e fora da escola. Que percepções Margarida, Girassol e Crisântemo tem quanto ao uso de jogos virtuais como um método para o ensino e aprendizado em química? Os relatos trazem as seguintes afirmativas:

"Considero bem aceitável para disciplina por facilitar a compreensão e atrair a atenção para os conteúdos" (Margarida).

"Acredito que o uso de jogos cria uma nova perspectiva sobre nossa disciplina e os assuntos nela discutidos. Muitas vezes os jogos prendem a atenção dos alunos fazendo com eles se concentrem e aprendam ainda mais" (Girassol).

"Vejo que é de fundamental importância pois vem como um complemento nesse processo de ensino e aprendizagem, trazendo o aluno mais próximo a sua realidade e diversificando os métodos de ensino" (Crisântemo).

A partir do relato dos professores, observa-se que estes veem os jogos virtuais como agentes facilitadores da aprendizagem, pois estimulam a motivação e aproximam o aluno do conteúdo abordado, sendo utilizados de forma ativa no ensino. Cunha (2012) afirma que o jogo favorece a construção de novas formas de se pensar, possibilitando o desenvolvimento e enriquecimento da personalidade do discente, e leva o professor a conduzir melhor suas aulas estimulando-as e favorecendo na avaliação de aprendizagem. O uso de jogos já era bastante perceptível nas salas de aula, contudo com as aulas remotas, resultado do covid-19, os professores tiveram que unir o analógico com o digital, e com isso potencializou o uso de jogos virtuais em suas aulas.

Neste aspecto, buscou-se compreender como a formação continuada dos docentes influenciou na aplicabilidade dos jogos virtuais na educação. Os relatos foram os seguintes:

"Sim. Fiz um curso a pouco tempo por a Secretária de Educação de Sobral que contemplava a gameficação. Me ajudou bastante a conhecer outras plataformas de jogos didáticos" (Margarida).

"Não, inicialmente afirmo que seria muito gratificante participar de uma formação assim, pois muitas vezes nossos alunos veem as aulas de química meio que chatas, e sabemos que não. Mas enriqueceria em muito nossas aulas" (Girassol).

"Já fiz várias formações desse tipo pelo CED e foi um momento de muito aprendizado e troca de conhecimentos" (Crisântemo).

A inserção dos jogos tecnológicos está bem mais presentes na formação continuada dos professores devido ao acesso à informação e a facilidade de acesso à tecnologia presente nas mídias digitais e redes sociais. A democratização do acesso à internet e o desenvolvimento da tecnologia na fabricação de dispositivos móveis, propiciou o surgimento dos jogos virtuais educativos que se apresentam de variadas formas. Tendo em vista que as crianças têm contato cada vez mais precoce com este novo mundo conquistado pelas tecnologias, faz se importante que os professores considerem a importância desses tipos de jogos para o processo de ensino e aprendizagem (Gonçalves \& Marco, 2016).

Os docentes se aproximam mais da tecnologia e com isso sua prática vem ao encontro com a realidade do uso da tecnologia em sala de aula. Pode-se observar pelos relatos, que mesmo os professores se reconhecendo como "tradicionais" eles estão se atualizando, buscando conhecimentos para com o uso de jogos virtuais em suas aulas. Esta realidade é um reflexo da nossa sociedade da Informação e comunicação, que reverbera na aproximação de crianças precocemente com os meios tecnológicos. Porém cabe o professor se atualizar e buscar utilizar pedagogicamente e didaticamente os jogos para o benefício de seus conteúdos bem como estabelecer estratégias de participação e avaliação da aprendizagem no uso desta metodologia (Savi \& Ulbricht, 2008). 
Foi a partir das reflexões, de como os docentes estão sendo formados diante da temática em questão, que se buscou saber sobre a frequência de seu uso em sala de aula. Suas afirmações nos possibilitam analisar sua percepção em relação ao momento mais adequado do uso de jogos virtuais em sala de aula. Os seguintes relatos forma apresentados:

\footnotetext{
"Depende da análise que o professor faz em relação a turma e conteúdo" (Margarida).

"Sim, dependendo do nível e da acessibilidade sim, o jogo tornaria a aula mais interessante" (Girassol).

"Sim, pois é algo que faz com que o aluno tenha um interesse maior pelo assunto" (Crisântemo).
}

Os relatos nos revelam a maturidade que está relacionada com o tempo de magistério, domínio do conteúdo e de percepção de sua turma. Vaillant e Garcia (2012) afirmam que a formação do docente ocorre ao longo da vida, em um processo de constantes modificações, que envolve apreensões de distintos saberes e estes direcionam o docente para a melhor estratégia de utilização de metodologias ativas em sala de aula.

\subsection{A percepção dos professores quanto a utilização dos jogos virtuais no processo de ensino-aprendizagem frente aos novos desafios impostos pela era digital e em tempos de pandemia}

Os jogos virtuais no processo se ensino e aprendizagem, assumem um papel preponderante nas aulas facilitando a apreensão de conteúdos facilmente, assim como pode favorecer a interação da turma, o espírito de cooperatividade e competitividade (Freitas \& Mancini, 2019). Os relatos abaixo trazem informações práticas sobre o uso dos jogos virtuais em sala de aula:

"Sim. Em sala de aula sempre usava Batalha Naval com perguntas de Química e de forma virtual uso bastante os quiz. Na batalha naval eles gostam bastante devido a competição, no quiz alguns não se sentem desafiados e outros tem receio de não se saírem bem" (Margarida).

"Sim, gosto de aplicar alguns em sala de aula, mais observo muito a participação dos alunos, alguns deles se mostram desmotivados mesmo pela insistência do professor, mas boa parte da turma participa ainda mais quando o jogo é atraente" (Girassol).

"Sim, eles reagiram com muita empolgação para aprender. Baralho de química” (Crisântemo).

Estes dados nos trazem o olhar dos docentes de uma forma mais prática sobre o uso dos jogos virtuais. Nas palavras de Bittar (2010), os professores ao estabelecerem a integração de uma nova estratégia ou ferramenta didática em sala de aula, devem levar em consideração as mudanças pedagógicas e os fatores que influenciam no processo de ensino-aprendizagem. E a ludicidade deve favorecer tais mudanças pedagógicas, perceptíveis na prática dos sujeitos desta pesquisa. Os relatos a seguir são provenientes da observação dos professores, quando os alunos estão envolvidos em atividades lúdicas:

"Considero os jogos muito favoráveis ao trabalho com raciocínio rápido, concentração do aluno e em motivá-lo a participar. Ao usar os jogos percebo um maior número de alunos querendo participar voluntariamente" (Margarida).

"Sim, dependendo do nível e da acessibilidade sim, o jogo tornaria a aula mais interessante (Girassol)."

"Sim, pois é algo que faz com que o aluno tenha um interesse maior pelo assunto (Crisântemo)."

Os relatos de Margarida, Girassol e Crisântemo exprimem seu olhar de forma mais prática quanto à aplicabilidade do jogo virtual e suas percepções quanto a aprendizagem dos discentes. Fraga (2010) afirma que quando o professor utiliza os 
jogos como uma nova prática educacional se estabelece uma relação prazerosa entre o educador e os alunos promovendo um clima de construção do conhecimento e despertando o querer-saber no sujeito, que tem sido muitas vezes fadado ao deverfazer, ou seja, a aprender. Quando o discente decide querer-jogar se estabelece um vínculo com os saberes a serem adquiridos através da ludicidade e o estudante consegue explorar um vasto mundo de informações e desenvolvimento de competências e habilidades.

Esta realidade se tornou presente na pandemia do COVID-19, levando os professores a pensarem sua prática docente de forma inovadora diante do ensino remoto, por meio de novas alternativas de levar o conhecimento aos alunos de uma forma mais interativa. Nessa perspectiva, os questionamentos foram direcionados para saber se os docentes utilizaram jogos durante a pandemia. Os relatos a posteriori são reflexões de sua utilização:

"Sim usei. Todos participaram até mesmo porque era uma avaliação, mas muito não gostaram da questão do tempo, mas adoraram o formato" (Margarida).

"Não tivemos essa oportunidade, devido muitos alunos estarem sem acesso [à internet], e a metodologia aplicada as vezes não nos permitiu usá-los" (Girassol).

“Os jogos eu utilizava mais para fazer revisão para as provas. A participação foi muito boa” (Crisântemo).

Margarida e Crisântemo informaram que utilizaram essa ferramenta de interação em sala de aula remota, contudo Girassol informou que faltou oportunidade para inseri-la em sua disciplina. Destacamos que em Girassol percebe-se uma realidade presente nos municípios do interior do Ceará, que é a falta de acesso, ou baixa conectividade com a internet, do qual impossibilita os professores e alunos à educação. Mesmo que o Governo do Estado do Ceará tenha vindo com a proposta de doação de chips de acesso à internet, muitos municípios sequer tenham uma torre de transmissão de rede móvel que atinjam a distritos e na própria sede do município. Tal realidade muitas vezes limita, ou até impossibilita o professor desenvolver atividades remotamente com suas classes (Clemente \& Cruz, 2021).

Finalizamos nossas reflexões com as discussões de Margarida, Girassol e Crisântemo, sobre o uso dos jogos virtuais na disciplina de química. Os docentes foram motivados a expressarem seus olhares quanto ao interesse no uso dos jogos virtuais na disciplina de química. Seus pensamentos estão mostrados a seguir.

"Pode atrair, mas não considero a única maneira de despertar o interesse do aluno...o mais importante é apresentar a Química como uma disciplina que está a nossa volta das formas mais simples e complexas" (Margarida).

"Os jogos virtuais devem necessariamente prender a atenção dos alunos e serem bem interessantes, visto que se não forem os alunos ficaram ainda mais desmotivados" (Girassol).

"Sabemos que a disciplina de química é vista como uma disciplina difícil por muitos alunos, portanto esses jogos eles quebram essa barreira existente tornando a disciplina mais simples e dessa forma trazendo um interesse maior por parte dos alunos em aprender" (Crisântemo).

Os jogos virtuais têm seu papel no processo de ensino e aprendizagem, contudo o professor se depara com muitas dificuldades em sua aplicabilidade e usabilidade em sala de aula, necessitando de mais recursos e formação continuada para aplicação e avaliação da aprendizagem através desses instrumentos lúdicos. A afirmativa de Crisântemo destaca que a química é "uma disciplina difícil por muitos alunos" e o jogo busca romper essa dificuldade, e assim fica claro que o jogo virtual consegue promover uma nova roupagem no processo educacional. Quando se trata das Ciências Exatas, a informática, os recursos digitais e a ludicidade podem ser fortes aliadas à medida que possibilitam a familiarização de conceitos abstratos ou de difícil assimilação (Lucena \& Azevedo, 2012). 
Pode-se perceber que o jogo virtual assume um papel importante na prática docente: um papel potencializador. Contudo, para que ocorra de forma exitosa, o educador precisa estar atualizado no tocante à uma formação inicial e continuada voltada para o uso das TDIC's, permitindo a apropriação dessas técnicas e o uso de metodologias ativas (como o uso de jogos virtuais), tornando a sua utilização acessível e facilitando a mediação dos conteúdos do currículo escolar, no caso em questão, vinculados ao ensino de química.

\section{Conclusão}

A pesquisa possibilitou explorar a percepção de professores de Química sobre a aplicabilidade e utilização de jogos virtuais no ensino de química, diante da realidade pandêmica vivenciada, e os resultados dessa investigação foram ao encontro dos objetivos traçados neste trabalho. A partir dos relatos coletados, observou-se que as professoras de química participantes da pesquisa conseguiram se reinventar e utilizaram jogos em suas aulas. Entretanto, mesmo aqueles que já realizaram algum tipo de formação continuada quanto ao uso destas tecnologias, sentiram algum tipo de dificuldade em sua aplicação.

Além disso, a pesquisa se propôs também a conhecer o perfil de formação dos professores e suas compreensões quanto o uso de jogos virtuais como ferramenta de ensino. Percebe-se que as práticas docentes tradicionais estão cada vez mais sendo superadas por um ensino pautado na utilização de tecnologias digitais. E que os docentes estão buscando se atualizar em relação as TDIC's e outras metodologias ativas em educação, como os jogos virtuais que definitivamente fazem parte da prática docente em decorrência do ensino remoto advindo com a pandemia do COVID-19.

$\mathrm{Na}$ investigação, procurou-se refletir também, a partir das afirmativas dos professores, sobre o papel dos jogos virtuais no ensino e aprendizagem de química diante das mudanças no ensino. Observou-se que o jogo virtual, conforme os investigados, assume um papel preponderante na prática docente no Ensino de química, potencializando de forma exitosa a aprendizagem dos alunos. Contudo o docente necessita de formações constantes voltadas ao uso das TICs, para que assim, o uso de jogos virtuais em suas disciplinas sejam ferramentas facilitadoras no processo de ensino de conteúdos específicos da química.

Desta forma, conclui-se que os jogos virtuais educativos para os professores de Química se mostraram eficientes e necessários, principalmente diante da realidade que se vivencia com a pandemia do COVID-19. Percebe-se que a presente investigação é somente a "ponta do iceberg", e que abre um leque para mais pesquisas com temáticas que relacionem a química, com o ensino remoto, com a realidade do COVID-19 e as percepções dos alunos, com a realidade virtual, entre outras.

Sugere-se para trabalhos futuros, a elaboração de estudos de caso em diferentes níveis de ensino da educação básica, que permitam compreender a percepção discente sobre o uso de jogos virtuais nas disciplinas de Ciências Naturais (Química, Física e Biologia), seus desafios e suas contribuições para a melhoria e aperfeiçoamento do processo de ensino-aprendizagem, na perspectiva de desenvolver no aluno o letramento científico e a criticidade frente aos fenômenos naturais, sociais e tecnológicos.

\section{Referências}

Benedetti Filho, E., Santos, C. G. P. dos, Cavagis, A. D. M., \& Benedetti, L. P. dos S. (2019). Desenvolvimento e aplicação de um jogo virtual no ensino de Química. Informática na Educação: Teoria \& Prática, 22(3), 144-157.

Bitencourte, A., Hinz, V. T., \& Lopes, J. L. B. (2018). Uma análise do uso das tecnologias móveis digitais em sala de aula no ensino médio de uma escola pública. Educar Mais, 2(1), 1-23. https://doi.org/https://doi.org/10.15536/reducarmais.2.2018.\%p.1273

Bittar, M. (2010). A escolha do software educacional e a proposta didática do professor: estudo de alguns exemplos em matemática. In Beline,W. \& Costa, N. M. L. Educação matemática, tecnologia e formação de professores: algumas reflexões (2 ed.). Campo Mourão, PR: Editora da Faculdade Estadual de Ciências e Letras de Campo Mourão - FECILCAM. 
Carlotto, M. S. (2011). Síndrome de Burnout em professores: prevalência e fatores associados. Psicologia: Teoria e Pesquisa, 27(4), 403-410.

Carvalho, L. A. de;, Santos, S. F. dos;, Oliveira, L. F. P., \& Galdino, M. E. R. (2019). Tecnologias Digitais de Informação e Comunicação (TDIC'S) e a sala de aula. Revista Perspectivas Online: Humanas \& Sociais Aplicadas, 9(26), 32-51. https://doi.org/10.25242887692620191876

Clemente, M. C. T., \& Cruz, G. D. da. (2021). A experiência de docentes em formação inicial com o ensino remoto: Refletindo sobre desafios em busca de soluções prováveis. Revista X, 16(3), 703-727. https://doi.org/10.5380/rvx.v16i3.79528

Cruz, J. M. de O. (2008). Processo de ensino-aprendizagem na sociedade da informação. Educação e Sociedade, 29(105), 1023-1042. https://doi.org/10.1590/s0101-73302008000400005

Cunha, M. B. da. (2012). Jogos no ensino de química: considerações teóricas para sua utilização em sala de aula. Química Nova na Escola, 34(2), 92-98. http://www.qnesc.sbq.org.br/online/qnesc34_2/07-PE-53-11.pdf

Domenico, A. S. D., Zamboni, T. M., \& Moreira, E. M. (2015). Os desafios atuais da profissão professor. Revista Educação \& Tecnologia, 15 , 9-17.

Fraga, D. (2010). Linguagem, jogo digital e educação linguística. In Aprendizagem em ambientes virtuais: compartilhando ideias e construindo cenários (2. ed.). Caxias do Sul, RS: Editora da Universidade de Caxias do Sul - EDUCS.

Freitas, J. L. A., \& Mancini, K. C. (2019). Contribuições da ludicidade no processo de ensino e aprendizagem de conhecimentos científicos e culturais. KiriKerê: Pesquisa em Ensino, 7, 104-122.

Gil, A. C. (2008). Métodos e Técnicas de Pesquisa Social (6 $6^{\mathrm{a}}$ ed.). São Paulo, SP: Editora Atlas.

Gonçalves, E. H., \& Marco, F. F. de. (2016). Jogos virtuais educativos: alternativa metodológica no ensino e aprendizagem da matemática nos anos iniciais do ensino fundamental. Anais do Encontro Nacional de Educação Matemática. Educação Matemática na Contemporaneidade: desafios e possibilidades. São Paulo, SP, Brasil, 12.

Jacinto Junior, S. G., Lucena, E. M. P. de, Alves, D. R., \& Morais, S. M. de. (2021). O ensino de ciências naturais na educação básica por meio de atividades lúdicas: uma revisão da literatura. Research, Society and Development, 10(6), e16110614643. https://doi.org/10.33448/rsd-v10i6.14643

Lima Filho, F. de S., Cunha, F. P. da, Carvalho, F. da S., \& Soares, M. de F. C. (2011). A importância do uso de recursos didáticos alternativos no ensino de química: uma abordagem sobre novas metodologias. Enciclopédia Biosfera, Centro Científico Conhecer, 7(12), 166-173. http://www.conhecer.org.br/enciclop/conbras1/a importancia.pdf

Lucena, G. L., \& Azevedo, M. S. (2012). QUIZmica: um jogo virtual auxiliando o ensino de Química. Revista Tecnologias na Educação, 7(4), 1-11. http://tecnologiasnaeducacao.pro.br/

Lüdke, M., \& André, M. E. D. A. (2013). Pesquisas em educação: uma abordagem qualitativa (2ª ed). Rio de Janeiro, RJ: Editora Pedagógica e Universitária.

Martins, C., \& Giraffa, L. M. M. (2014). Gamificação nas práticas pedagógicas em tempos de cibercultura: proposta de elementos de jogos digitais em atividades gamificadas. Anais do Seminário de Jogos Eletrônicos, Educação e Comunicação. Salvador, BA, Brasil, 11. https://doi.org/10.5753/cbie.wcbie.2014.51

Minayo, M. C. de S. (2001). Ciência, técnica e arte: o desafio da pesquisa social. In Pesquisa Social. Teoria, método e criatividade (18th ed., p. 96).

Nicola, J. A., \& Paniz, C. M. (2016). A importância da utilização de diferentes recursos didáticos no ensino de ciências e biologia. Inovação e Formação Revista do núcleo de educação a distância da Unesp, 2(1), 355-381.

Oliveira, D. A. (2006). Regulação educativa na América Latina: repercussões sobre a identidade dos trabalhadores docentes. Educação em Revista, 44(dez), $209-227$.

Palú, J., Schütz, J. A., \& Mayer, L. (2020). Desafios da educação em tempos de pandemia. In E. Ilustração (Ed.), Desafios da educação em tempos de pandemia (1 ${ }^{\mathrm{a}} \mathrm{ed}$.). https://doi.org/10.46550/978-65-991146-9-4

Person, V. A., Bremm, D., \& Güllich, R. I. da C. (2019). A formação continuada de professores de ciências: elementos constitutivos do processo. Revista Brasileira de Extensão Universitária, 10(3), 141-147. https://doi.org/10.24317/2358-0399.2019v10i3.10840

Prensky, M. (2012). Aprendizagem baseada em jogos digitais (1 $1^{\mathrm{a}}$ ed). São Paulo, SP: Editora SENAC.

Romano, C. G., Carvalho, A. L., Mattano, I. D., Chaves, M. R. M., \& Antoniassi, B. (2017). Perfil químico: um jogo para o ensino da Tabela Periódica. Revista Virtual de Química, 9(3), 1235-1244. https://doi.org/10.21577/1984-6835.20170072

Santos, A. G. dos;, \& Melo, S. C. da S. (2020). O ensino de Ciências e a peça teatral "Heróis Da Ciência": olhares dos estudantes com deficiência. Revista Educação e (Trans)Formação, Dossiê Tem(dez), 54-71.

Savi, R., \& Ulbricht, V. R. (2008). Jogos digitais educacionais: benefícios e desafios. Revista novas tecnologias na educação, 6(2), 1-10. https://doi.org/10.22456/1679-1916.14405

Scherer, S., \& Silva Miranda, C. S. (2013). Jogos virtuais e educação nas escolas. Ação midiática: estudos em comunicação, sociedade e cultura, 2(5), 1-16.

Shaw, G. L., \& Ribeiro, M. S. de S. (2014). Games no ensino de ciências: desafios e possibilidades. Revista de Educação da Universidade Federal do Vale do São Francisco, 4(6), 98-110.

Vaillant, D., \& Garcia, C. M. (2012). Ensinando a ensinar: as quatro etapas de uma aprendizagem (1 ${ }^{\text {a }}$ ed). Curitiba, PR: Editora da Universidade Tecnológica Federal do Paraná - EDUTFPR. 